\title{
The vomeronasal organ of greater bushbabies (Otolemur spp.): Species, sex, and age differences
}

\author{
TIMOTHY D. SMITH ${ }^{1,2, *}$, KUNWAR P. BHATNAGAR ${ }^{3}$, ANNE M. $^{2}$ \\ BURROWS ${ }^{4,2}$, KRISTIN L. SHIMP ${ }^{1}$, JOHN C. DENNIS ${ }^{5}$, MATTHEW A. \\ SMITH $^{6}$, LISETTE MAICO-TAN ${ }^{1}$ and EDWARD E. MORRISON ${ }^{5}$ \\ ${ }^{1}$ School of Physical Therapy, Slippery Rock University, Slippery Rock, PA 16057; ${ }^{2}$ Department of Anthropology, University of \\ Pittsburgh, Pittsburgh, PA 15260; ${ }^{3}$ Department of Anatomical Sciences and Neurobiology, University of Louisville School of Medicine, \\ Louisville, KY 40292; ${ }^{4}$ Department of Physical Therapy, Duquesne University, Pittsburgh, PA 15282; ${ }^{5}$ Department of Anatomy, \\ Physiology and Pharmacology, College of Veterinary Medicine, Auburn University, Auburn, AL 36849; ${ }^{6}$ Center for the Neural Basis of \\ Cognition, Carnegie Mellon University, Pittsburgh, PA \\ timothy.smith@sru.edu
}

Received 3 January 2005; revised 31 March 2005; accepted 4 April 2005

\begin{abstract}
The present study examined interspecies, intersexual, and age-related changes in size of the vomeronasal neuroepithelium (VNNE) of two species of greater bushbabies (genus Otolemur, Infraorder Lorisiformes, Suborder Strepsirrhini). Tissue blocks containing the vomeronasal organs of nine $O$. crassicaudatus ( 8 adults, 1 neonate) and ten $O$. garnettii ( 9 adults, 1 neonate) were studied by means of serial paraffin sectioning and computer-based reconstruction of VNNE volume. In addition, the immunoreactivity of the VNNE to two neuronal markers, neuron-specific beta tubulin (BT) and olfactory marker protein (OMP) was compared between species, sexes, and ages. Results indicated that a clear VNNE is present at birth in both species, and OMP immunoreactivity was verified in O. garnettii at birth. Male and female adults of both species showed OMP-immunoreactive and BT-immunoreactive neurons in the VNNE. Immunohistochemical findings indicated that all males and the youngest females had the thickest VNNE, especially at the marginal junctions with the receptor-free epithelium. Results of a 2-way Analysis of Variance (ANOVA, species x sex) revealed no significant differences in VNNE length or volume between species, but $O$. crassicaudatus had significantly $(p<0.05)$ greater palatal length. Significant $(p<0.05)$ differences also were found between sexes in VNNE volume, but no significant differences in palatal length or VNNE length. The distribution of VNNE volume against age indicated that the sex differences were more pronounced in O. crassicaudatus than $O$. garnettii. For both species and sexes, distribution of VNNE volume against age suggested an age-related reduction in volume. These findings demonstrate postnatal plasticity in VNNE size in Otolemur that is reminiscent of that found for olfactory structures in some rodents. Bushbabies or other strepsirrhine primates may offer an opportunity for further understanding of behavioral correlates of VNNE postnatal plasticity, which may represent primitive functional characteristics of the order Primates.
\end{abstract}

Abbreviation: BT, beta tubulin; IHC, immunohistochemistry; OMP, olfactory marker protein; RFE, receptor-free epithelium; VNNE, vomeronasal neuroepithelium; VNO, vomeronasal organ; VRN, vomeronasal receptor neurons.

\section{Introduction}

Quantitative differences in the vomeronasal organ ${ }^{1}$ (VNO) have been postulated to reflect differences in chemosensory abilities (see Dawley, 1998; Smith et al., 2001a). In many species, volume, cross-sectional area, receptor neuron density, and total number of receptor neurons in the vomeronasal neuroepithelium (VNNE) are greater in males than females (Dawley \& Crowder, 1995; Segovia \& Guillamón, 1982; Tai et al., 2004), although the reverse is true in some rodents (Maico et al.,
2003). Such differences have been reported for both absolute and/or relative (e.g., to body size) measurements (but see Smith \& Bhatnagar, 2004, for a discussion on the appropriateness for scaling data on sensory organs). A few studies have documented age-related changes in VNO size of rodents (Addison and Rademaker, 1927; Weiler et al., 1999a; Wilson and Raisman, 1980). To date, no studies have investigated such data in non-human primates.

\footnotetext{
${ }^{*}$ To whom correspondence should be addressed.
} 
Quantitative studies on the peripheral (VNO) and central elements (accessory olfactory bulb) of the primate vomeronasal system are few and have focused on small samples. Reviews of these data indicate that, among primates, strepsirrhines (lemurs and lorises) have relatively and absolutely the largest VNOs and accessory olfactory bulbs (see Dawley, 1998; Stephan et al., 1982). Still fewer studies examined sexual dimorphism of primate VNOs. Several studies examined VNO size in prenatal humans (Sherwood et al., 1999; Smith et al., 1996, 1997) and mouse lemurs (Smith et al., 2001b). Only the human VNO was quantified in a large sample of adults, but no significant length differences were found between sexes (Abolmaali et al., 2001).

Generally, quantitative studies have used a measure of the receptor neuron population size (or some proxy for it such as volume) to estimate and compare the magnitude of chemosensory function in the VNO among taxa or between sexes. This practice is based on a positive relationship between receptor neuron population size and olfactory sensitivity (Meisami, 1989; Meisami et al., 1990). However, size measurements alone ignore certain biological aspects of vomeronasal receptor neurons, such as maturational state. To that end, the present study examines size and neuronal marker expression in the VNNE of greater bushbabies (Otolemur crassicaudatus and $O$. garnettii), nocturnal strepsirrhines that rely heavily on chemosensory modes of communication (Eaton et al., 1973; Watson et al., 1999). This genus was selected because it was previously noted to possess well-developed VNOs (Dennis et al., 2004; Hedewig, 1980a), and a dispersed multi-male social system (Müller \& Thalmann, 2000; Nash \& Harcourt, 1986). The polygamous mating behavior typified by this social system was identified previously as a possible correlate of sexual dimorphism in the VNO (Maico et al., 2003; Tai et al., 2004). Herein, species, sex, and age variation in VNNE size is reported for the first time in a non-human primate.

\section{Methods}

\section{ANIMALS}

The sample included eight adult ( 3 males, 5 females) and one male neonatal $O$. crassicaudatus and nine adult (5 males, 4 females) and one male neonatal $O$. garnettii. For the present study, cadaveric tissues were studied from adult animals euthanized after use in other studies at Duke University Medical Center (see Schmechel et al., 1996, for details regarding animal care), or from infant animals that died of natural causes at Duke University Primate Center. Those animals obtained from Duke University Medical Center were the subjects of studies on the natural aging effects on brain tissue with no experimental manipulations on the live animals (Schmechel et al., 1996). As such, cadaveric tissues from a broad age range of specimens was available. An effort was made to age-match males and females of each species, but some animals (male $O$. crassicaudatus, and $>14$ year old female $O$. garnettii) were in limited supply. Prior to purchase, the brains were removed but the basicrania and facial regions remained intact.

\section{DISSECTION AND HISTOLOGICAL PROCEDURES}

Before removing the nasal septa, the skin was removed to expose the available osseous landmarks. In all cases, palatal length (distance between prosthion and the posterior midline point of the palate) was measured using digital calipers. Other measurements were taken where the skull was intact for that purpose. It has been argued elsewhere that scaling to body size needlessly distorts VNNE data when comparing adult samples (Maico et al., 2003; Smith \& Bhatnagar, 2004). It was argued that olfactory structures simply do not scale in proportion to body size in the same manner as, for example, neural pathways related to somatosensation (Smith \& Bhatnagar, 2004). However, since a number of studies have examined VNO size in the context of body size (Smith et al., 2001a; Weiler et al., 1999a), these palatal measurements taken on the sample herein were used to determine if there was sexual dimorphism of nasal cavity length.

Nasal septa and palates were removed as one piece from each adult head using a chisel and forceps. In some adult and both infants, entire halves of nasal fossae, including the septum, were used. Tissue blocks were decalcified using a formic acid-sodium citrate solution. Following decalcification, tissue blocks were dehydrated, cleared and embedded in paraffin using a vacuum oven. Sections were cut serially at $10 \mu \mathrm{m}$, except in seven specimens in which the large size of the tissue block required thicknesses of 12 to $14 \mu \mathrm{m}$ to maintain sectional integrity. Every 10th section was mounted on glass slides and stained alternately with hematoxylin-eosin or Gomori trichrome procedures.

\section{QUANTITATIVE METHODS AND ANALYSIS}

After identification of the serial end points of the VNNE (see below), selected intervening sections were mounted on slides to ensure that the rostral and caudal ends of the VNNE could be isolated within an error of 50-70 $\mu \mathrm{m}$. Each series was examined to identify the sections that contained VNNE. The right VNNE of each section was magnified $(\times 100)$ and digitally photographed using a Leica DMLB photomicroscope with a DKC-5000 Catseye Digital Still Camera System (Sony Electronics Inc., Montvale NJ). VNNE area (in $\mathrm{mm}^{2}$ ) was measured in each section by using Scion Image software $(\mathrm{NIH}$, www.scioncorp.com) to digitize the perimeter of the VNNE shown in the micrograph (calibration was made using a micrograph of a stage micrometer at $\times 100$ ). By multiplying the VNNE area of each section $X$ the distance (in $\mathrm{mm}$ ) to the next section, segmental volumes were obtained. The sum of all segmental volumes is the total VNNE volume, as reported in Table 2.

Vomeronasal receptor neuron (VRN) nuclei were counted in each specimen sectioned at $10 \mu \mathrm{m}$ for a comparison of VRN nuclear density among specimens. The first rostrocaudal section in which VNNE was found was designated as "zero percent" of VNNE length and the last section was designated as "100 percent." Based on these start and stop points, sectional levels for the 25,50 , and 75 th percentiles were calculated; these levels were arbitrarily selected to 
perform counts of receptor neuron nuclei. Every attempt was made to use the exact section of the VNNE for collecting data. However, in cases where these sections were damaged or difficult to photograph, the previous or next section was used. At each percentile, the VNO was magnified $(\times 300)$ and digitally photographed using Pixera Visual Communications Suite 2.0 software. Micrographs were taken from three parts of the VNNE (dorsal, middle, and ventral) and these three measurements were recorded for each percentile $(25,50$, and 75 th percentile), making a total of nine recordings for each specimen. After digitally photographing a stage micrometer, a $30 \times 30 \mu \mathrm{m}$ grid was constructed using Adobe Photoshop 8.0 (Adobe Systems, San Jose, CA). This grid was then superimposed over the three regions of VNNE (dorsal, middle, ventral). Receptor cell nuclei were located in the basal twoto one-third of the VNNE with nuclei that appear rounder than more apical supporting cells. The grid was positioned in a manner that excluded nuclei of supporting cells or basal cells. A VRN was counted if at least half of its nucleus fell in within the borders of the grid. Using the Adobe Photoshop paintbrush tool, nuclei were marked during the counting to avoid counting a cell nucleus more than once. Counts were double-checked by changing the paint color and re-counting the marked nuclei. Correction factors were not used for nuclear counts since only preliminary comparisons were made using selected specimens in the sample. Prior to calculation of VRN nuclear densities, scatter plots were generated using SPSS 11.0 software (SPSS, Inc., Chicago, IL) and exami- ned for possible outlying data points. Dixon's test (Sokal \& Rohlf, 1981) was used to determine whether these should be removed. Subsequently, average nuclear counts were calculated from all nine measurements (dorsal, middle, and ventral counts for each of three percentiles) for each specimen measured. The number of VRNs per $30 \times 30 \mu \mathrm{m}$ grid was then converted to the number per $\mathrm{mm}^{2}$ for tabulation (Table 1).

Using the same sectional levels, measurements of VNNE thickness and thickness of the neuronal portion of the VNNE were measured according to the methods of Weiler et al. (1999a). Briefly, the neuronal portion was measured from the basement membrane to the basal boundary of the supporting cell nuclei. The total VNNE thickness was measured from the basement membrane to the apical surface of the VNNE. Using Scion Image, the files used for cellular counts (see above) were used to take thickness measurements for dorsal, middle, and ventral portions of the VNNE at each percentile. The lengths were calibrated using a micrograph of a stage micrometer. Average neuronal layer thicknesses (in $\mu \mathrm{m}$ ) and the percentage of neuronal layer/total VNNE thickness $\times 100$ were calculated for each specimen (Table 1).

The diameter of the VRN nucleus was measured from sections midway along the VNNE rostrocaudal axis. For measurement, one or more micrographs of each VNNE were taken at $\times 1000$. In Scion Image, this image was opened and the maximum diameter was measured in five nuclei. Nuclei were

Table 1. : Age, sex, palatal length, and VNO measurements for two species of bushbabies.

\begin{tabular}{|c|c|c|c|c|c|c|c|c|}
\hline $\begin{array}{l}\text { Specimen } \\
\#\end{array}$ & $\begin{array}{l}\text { Age } \\
\text { (years) }\end{array}$ & Sex & $\begin{array}{l}\text { palatal } \\
\text { length } \\
(\mathrm{mm})\end{array}$ & $\begin{array}{l}\text { VNO } \\
\text { duct } \\
\text { length } \\
(\mathrm{mm})\end{array}$ & $\begin{array}{l}\text { VNNE } \\
\text { receptor } \\
\text { neuron } \\
\text { nuclei/mm² }\end{array}$ & $\begin{array}{l}\text { neuronal } \\
\text { layer } \\
\text { thickness } \\
(\mu \mathrm{m})\end{array}$ & $\begin{array}{l}\text { neuronal } \\
\text { layer/total } \\
\text { thickness } \\
\times 100(\text { in \%) }\end{array}$ & $\begin{array}{l}\text { VRN } \\
\text { diameter }^{1} \\
(\mu \mathrm{m})\end{array}$ \\
\hline \multicolumn{9}{|c|}{ Otolemur crassicaudatus } \\
\hline${ }^{*} 2789$ & 11 & $\mathrm{M}$ & 30.26 & 0.73 & 12,592 & 46.45 & 62.5 & 7.90 \\
\hline 2845 & 9 & $\mathrm{M}$ & 30.28 & 1.44 & - & 43.21 & 62.7 & 7.69 \\
\hline *2868 & 8 & $\mathrm{M}$ & 30.87 & 1.10 & 10,122 & 42.14 & 60.8 & 9.68 \\
\hline 2724 & 13 & $\mathrm{~F}$ & 29.03 & 1.12 & 12,715 & 40.74 & 62.9 & 9.06 \\
\hline$*, \dagger 2766$ & 12 & $\mathrm{~F}$ & 30.98 & 1.40 & - & - & - & 9.87 \\
\hline 2855 & 9 & $\mathrm{~F}$ & 31.86 & 0.70 & - & 39.54 & 60.3 & 9.85 \\
\hline 2882 & 6 & $\mathrm{~F}$ & 29.66 & 1.20 & 11,172 & 44.19 & 59.1 & 9.69 \\
\hline 2802 & 11 & $\mathrm{~F}$ & 28.75 & 1.44 & - & 33.31 & 59.0 & 8.97 \\
\hline † 2808 & $0(\mathrm{n})$ & $\mathrm{M}$ & 12.00 & 0.20 & - & - & - & - \\
\hline \multicolumn{9}{|c|}{ Otolemur garnettii } \\
\hline 8860 & 8 & $\mathrm{M}$ & 25.38 & 1.34 & - & 39.29 & 59.9 & 8.03 \\
\hline 15 & 20 & $\mathrm{M}$ & 26.68 & 1.75 & - & 41.53 & 63.1 & 9.49 \\
\hline 517 & 20 & $\mathrm{M}$ & 27.81 & 1.68 & - & 35.28 & 61.3 & 9.37 \\
\hline 8862 & 7 & $\mathrm{M}$ & 28.14 & 1.90 & 13,085 & 38.77 & 58.9 & 7.86 \\
\hline${ }^{*} 8859$ & 8 & $\mathrm{M}$ & 25.55 & 1.90 & 11,974 & 40.23 & 56.7 & 8.41 \\
\hline 2861 & 14 & $\mathrm{~F}$ & 26.39 & 1.60 & 12,962 & 34.0 & 59.5 & 9.71 \\
\hline 8834 & 8 & $\mathrm{~F}$ & 25.54 & 1.06 & 12,344 & 44.22 & 59.5 & 8.34 \\
\hline 8701 & 13 & $\mathrm{~F}$ & 26.64 & 1.38 & - & 23.36 & 62.0 & 8.59 \\
\hline${ }^{*} 8813$ & 11 & $\mathrm{~F}$ & 25.98 & 2.15 & 13,332 & 36.0 & 59.5 & 8.96 \\
\hline${ }^{*} \mathrm{Og} 101$ & $0(\mathrm{n})$ & $\mathrm{M}$ & 12.00 & 0.50 & 19,722 & 31.01 & 61.9 & 5.73 \\
\hline
\end{tabular}

* indicates specimens used in IHC procedures; n, neonatal; M, male; F, female; ${ }^{\dagger}$ VNNE data unavailable due to damaged end points.

${ }^{1}$ At level of nucleus. 
measured only if they were sharply in focus and nucleoli were visible. The measurement was calibrated using a micrograph of a stage micrometer at $\times 1000$.

A 2-way Analysis of Variance (ANOVA)(species x sex) was used to compare palatal length, VNNE length, and VNNE volume among groups. Differences were considered significant at $p<0.05$. VRN numbers were not statistically compared since only a small portion of the whole sample (a total of four males and five females from both species) were used for calculating this number. ${ }^{2}$

\section{IMMUNOHISTOCHEMISTRY}

For immunohistochemistry (IHC), mounted tissue sections were deparaffinized in Hemo-D (Scientific Safety Products,
Pittsburgh, PA), hydrated to distilled water $\left(\mathrm{dH}_{2} \mathrm{O}\right)$. To abolish endogenous peroxidase-like activity, the sections were incubated in absolute methanol made to $0.9 \%$ hydrogen peroxide $\left(\mathrm{H}_{2} \mathrm{O}_{2}\right)$ for 20 minutes at room temperature $(\mathrm{RT}=23.5$ to $25^{\circ} \mathrm{C}$ ). Subsequently, the tissues were washed in $\mathrm{dH}_{2} \mathrm{O}$ then in $10 \mathrm{mM}$ phosphate buffered saline (PBS) $(2.7 \mathrm{mM} \mathrm{KCl}$, $137 \mathrm{mM} \mathrm{NaCl}$; pH 7.4) (Sigma, St. Louis). Tissues to be analyzed by epifluoresence microscopy were not incubated in $\mathrm{H}_{2} \mathrm{O}_{2} /$ methanol but transferred from $\mathrm{dH} 2 \mathrm{O}$ directly to PBS. All tissues were incubated for 20 minutes in the appropriate blocking solution (5\% normal serum (Sigma, St. Louis) of the species in which the secondary antibody was made and 2.5\% BSA (Sigma, St. Louis) in PBS) then washed briefly in PBS. The primary antibody, appropriately diluted in blocking solution, was applied and the tissue sections
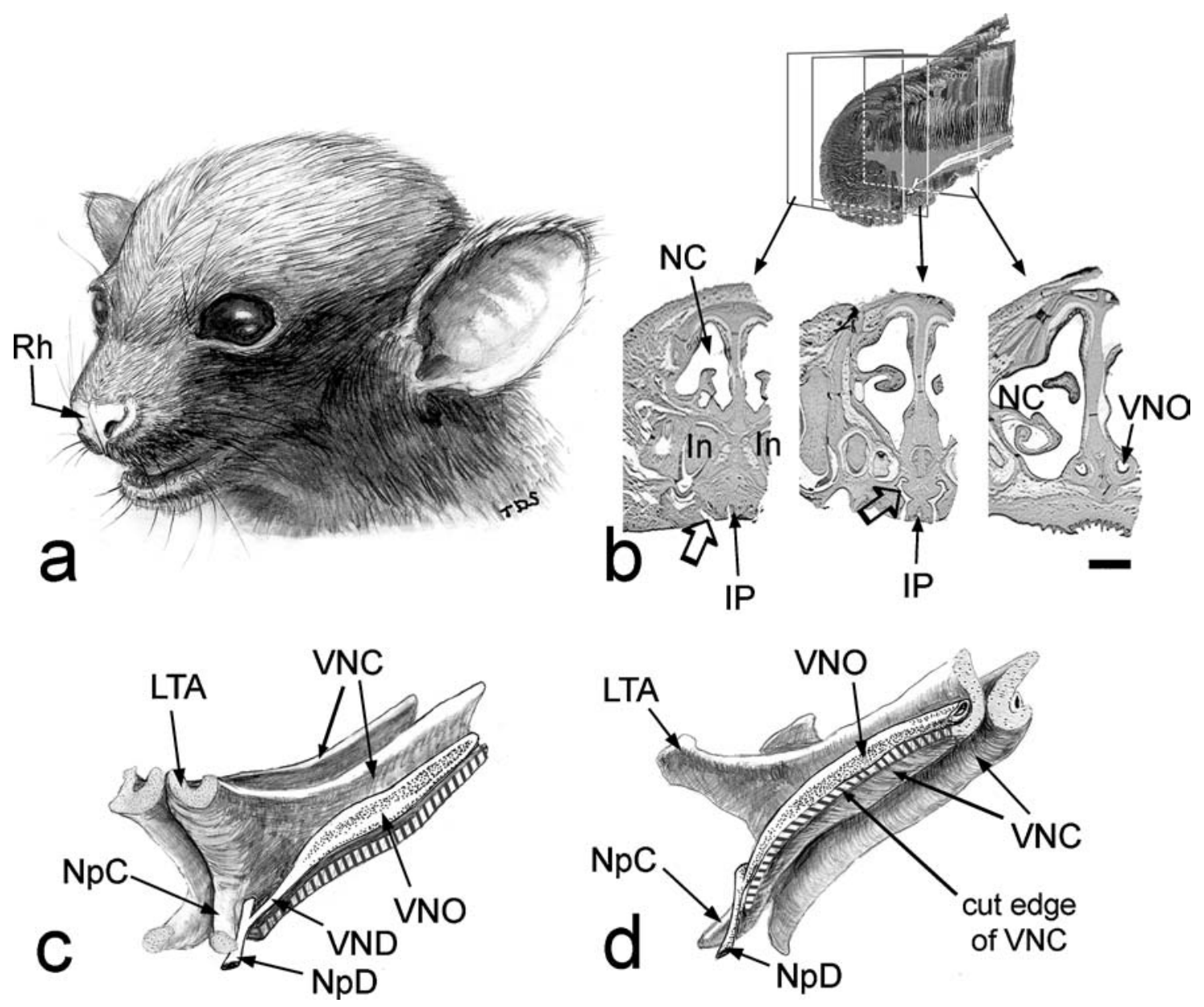

Fig. 1. (a) Superficial view of the face of an infant Otolemur garnettii. Note the pronounced sensory structures of the face, which include a hairless rhinarium $(\mathrm{Rh})$. Note the midline groove of the $\mathrm{Rh}$, which is hypothesized to allow fluids with non-volatile chemostimuli to flow from the external nose to the incisive papilla (b, IP), found in the oral cavity. This connection is facilitated by a spatial separation of the upper central incisors (b, In). b) A computerized three-dimensional reconstruction of the nasal cavity of an infant bushbaby (see top inset, 1b, shown in the same orientation as 1a) with 3 cross-sectional levels showing the beginning of the IP, the nasopalatine duct (open arrows) and the vomeronasal organ (VNO). c,d) show anterorlateral and posterolateral views of the VNO and associated cartilages in the infant shown in $1 \mathrm{~b}$ (redrawn after computer reconstructions). Only the left VNO is shown, with its connection to the nasopalatine duct (NpD) via the vomeronasal duct (VND). Therefore, the VNO does not communicate directly with the nasal cavity (as in rodents), but rather indirectly with both the nasal and oral cavities via the NpD. The VNO is exposed in 1c and 1d by removal of the lateral portion of the vomeronasal cartilage (VNC). The VNC is anteriorly continuous with the lamina transversalis anterior (LTA) and nasopalatine cartilage $(\mathrm{NpC})$. NC $=$ nasal cavity. Scale bar, $1 \mathrm{~b}$ (for all three cross-sections) $=1 \mathrm{~mm}$. 

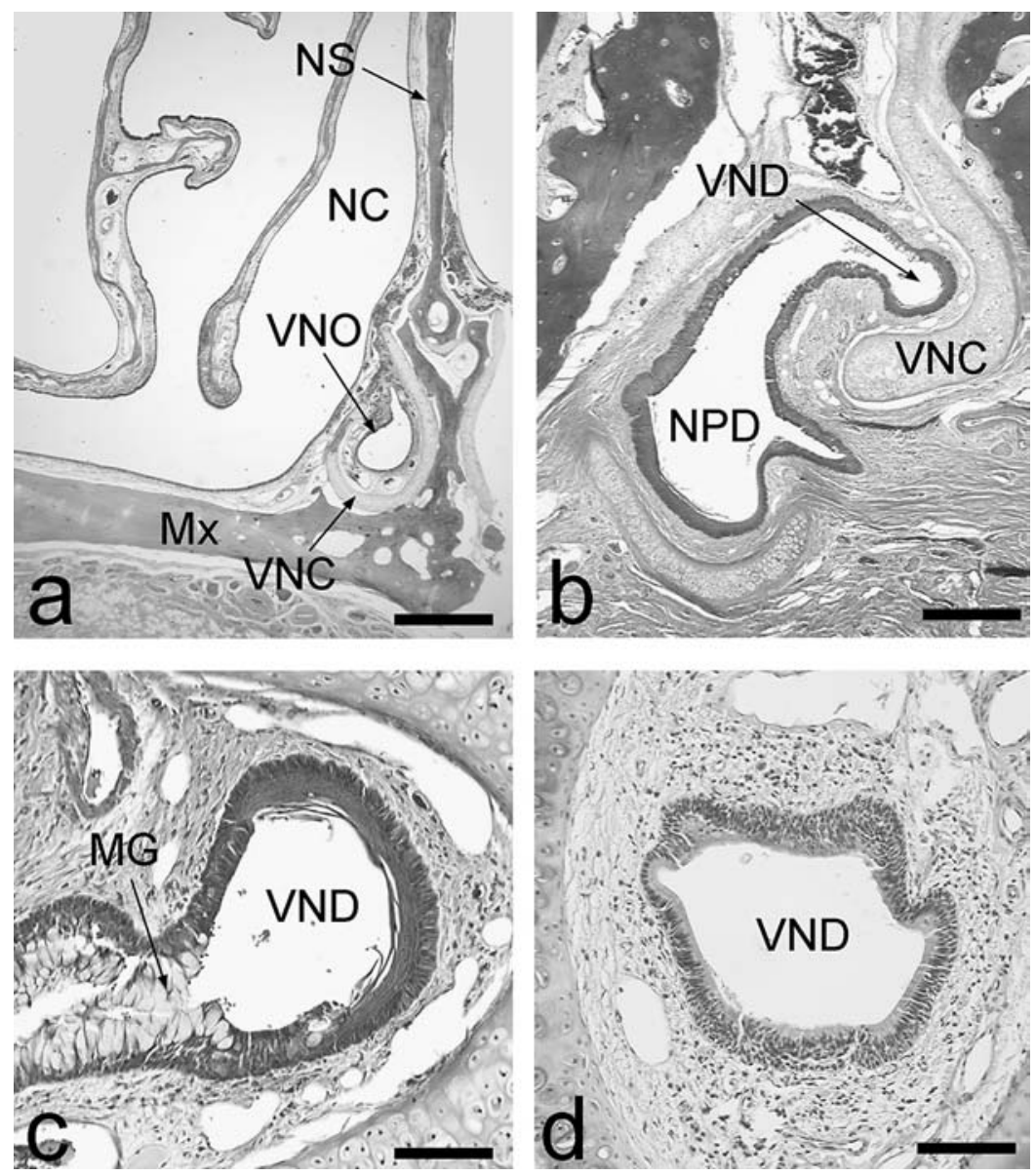

Fig. 2. (a) Coronal section of right nasal fossa of an adult female O. garnettii, illustrating position of right vomeronasal organ (VNO) at the base of the nasal septum (NS), mostly surrounded by vomeronasal cartilage (VNC). (b) Right vomeronasal duct (VND) of an adult $O$. crassicaudatus, showing its communication with the nasopalatine duct (NPD); (c) Left VND of same specimen showing the stratified squamous lining (note partially keratinized surface) and mucous glands (MG). (d) Right VND of an adult male O. garnettii, showing the pseudostratified columnar/stratified squamous morphology. Mx, maxilla; NC, nasal cavity; Scale bars: a, $800 \mu \mathrm{m} ; \mathrm{b}, 400 \mu \mathrm{m} ; \mathrm{c}, \mathrm{d}, 100 \mu \mathrm{m}$.

were left overnight at room temperature. For double label olfactory marker protein/beta tubulin (OMP/BT) assays, sections were incubated overnight in anti-OMP (gift of Dr. Frank Margolis) and then in anti-BT for one hour at room temperature. Sections to be analyzed with bright field optics were treated with biotinylated secondary an- tibodies (Vector, Burlingame, CA) diluted 1:200 then with $A B C$ Elite reagent (Vector, Burlingame, $C A$ ), reacted with diaminobenzidine (Vector, Burlingame, CA), dehydrated, and mounted with VectaMount (Vector, Burlingame, CA). Sections to be analyzed using epifluoresence microscopy were incubated for one hour with appropriate Alexa-conjugated

Table 2. : means of palatal and VNNE measurements with results of 2-way ANOVA.

\begin{tabular}{|c|c|c|c|c|c|c|c|c|}
\hline & \multicolumn{3}{|c|}{ Otolemur crassicaudatus } & \multicolumn{2}{|c|}{ Otolemur garnettii } & \multicolumn{2}{|c|}{$F$ values } & \multirow[b]{2}{*}{ Spp $\times$ Sex } \\
\hline & Males & & Females & Males & Females & Species & Sex & \\
\hline & \multicolumn{3}{|c|}{ Mean $(+/-S D)$} & \multicolumn{2}{|c|}{ Mean $(+/-S D)$} & & & \\
\hline PL (mm) & 30.5 & $(0.35)$ & $29.8(1.41)$ & 26.7 & $26.1 \quad(0.48)$ & $48.64^{*}$ & $1.46 \mathrm{~ns}$ & $0.01 \mathrm{~ns}$ \\
\hline VNNEL (mm) & 7.9 & (1.34) & $6.61(1.48)$ & 6.34 & $6.15(0.37)$ & $4.36 \mathrm{~ns}$ & $2.36 \mathrm{~ns}$ & $1.30 \mathrm{~ns}$ \\
\hline $\operatorname{VNNEV~}\left(\mathrm{mm}^{3}\right)$ & 0.46 & $(0.1)$ & $0.30(0.11)$ & 0.36 & $0.27(0.19)$ & $1.62 \mathrm{~ns}$ & $6.30^{*}$ & $0.71 \mathrm{~ns}$ \\
\hline
\end{tabular}

*Significantly different $(p<0.05)$; ns, not significantly different $(p>0.05)$; PL, palatal length; VNNEL, vomeronasal neuroepithelial length; VNNEV, vomeronasal neuroepithelial volume. 

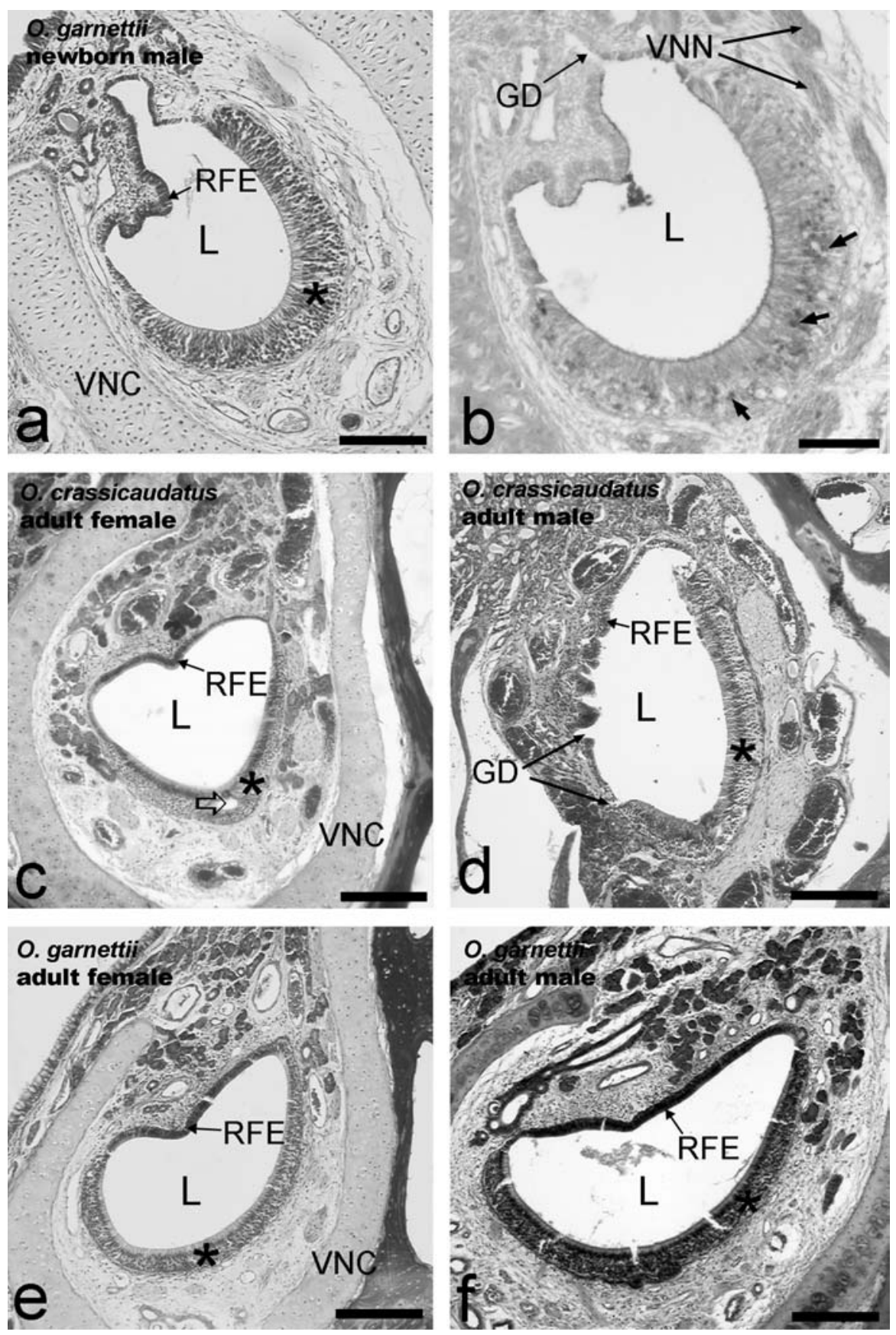

Fig. 3. (a) Coronal section of VNO in neonatal male O. garnettii. Note the clearly identifiable vomeronasal neuroepithelium $\left(^{*}\right)$ and receptor-free epithelium (RFE). (b) Coronal section of VNO in same specimen as $3 a, 30 \mu \mathrm{m}$ caudal, prepared with OMP immunostain. Note OMP-immunoreactive cells (short arrows) in the VNNE as well as the weakly OMP-immunoreactive vomeronasal nerves (VNN). (c) Coronal section of $\mathrm{VNO}$ in adult female O. crassicaudatus, compared to (d) coronal section of VNO in an adult male $O$. crassicaudatus. Note the thicker, more extensive VNNE in the male. The VNNE of the female $O$. crassicaudatus possesses a diverticulum, a feature found in most specimens (open arrow, 3c). (e) Coronal section of VNO in adult female adult $O$. garnettii compared to (f) Coronal section of VNO in adult male $O$. garnettii. Note that this female had an more extensive VNNE than the female shown in 3c. VNC, vomeronasal cartilage. Scale bars: $\mathrm{a}, 100 \mu \mathrm{m} ; \mathrm{b}, 70 \mu \mathrm{m} ; \mathrm{c}-\mathrm{f}, 200 \mu \mathrm{m}$.

secondaries (Molecular Probes) diluted at 1:500, mounted with VectaShield (Vector, Burlingame, CA), and sealed with clear nail polish. Tissues were examined with a Nikon Eclipse E600 microscope equipped with immunofluoresence. Images were made with a RT Slider digital camera (Diagnostic In- struments, Sterling Heights, MI) using Spot Advanced software and processed with Adobe Photoshop 8.0. Control for nonspecific secondary antibody binding was accomplished by incubating some sections in blocker without a primary antibody. 


\section{Results}

All but two of the specimens were suitable for volumetric reconstruction (Table 1). A more extensive threedimensional reconstruction of the nasal fossa of an infant $O$. garnettii was accomplished to demonstrate spatial relationships of the VNO (Fig. 1). The infant $O$. crassicaudatus had a clearly identifiable VNNE, useful for VNNE length measurement, but poor apical preservation of the VNNE precluded area/volume measurement. One adult female $O$. crassicaudatus had damaged caudal-most sections of the VNNE which prevented measurement, but the specimen was useful for other measurements and IHC.

In the coronal plane, the bilateral VNOs were situated at the base of the nasal septum, above the level of the palatal process of the maxillary bone, and were mostly encircled by the vomeronasal cartilages (Figs. $1 \mathrm{~b}-\mathrm{d}$ and $2 \mathrm{a})$. The VNOs communicated indirectly with both the nasal and oral cavities. This connection occurred rostrally, where each VNO narrowed into a nonsensory "vomeronasal duct" that opened to the nasopalatine duct on right or left sides (Figs. 1b-d and $2 b-d)$. The vomeronasal duct was lined with stratified squamous epithelium, which was partially keratinized in O. crassicaudatus (Fig. 2c). More proximal to the VNO entrance, the duct was lined with mixed stratified and pseudostratified columnar epithelium (Fig. 2d). In $O$. crassicaudatus, the duct also contained intraepithelial mucous glands near the entrance to the nasopalatine duct (Fig. 2c). These mucous glands were not present in O. garnettii. Both species had glandular ducts communicating with the vomeronasal duct just rostral to the VNNE, sparsely distributed ducts throughout the neuroepithelial region of the $\mathrm{VNO}$, and also one or more caudal ducts draining glandular secretions to the VNO lumen.

The VNO of both species of Otolemur was welldeveloped with respect to division of neuroepithelium and receptor-free epithelium. In coronal sections, males of both species generally appeared to have greater thickness of the VNNE than females (Figs. 3c-f and $5 \mathrm{a}-\mathrm{d})$. Density of receptor neuron nuclei ranged from 10,112 to 12,715 per $\mathrm{mm}^{2}$ in O. crassicaudatus and from 11,974 to 13,332 per $\mathrm{mm}^{2}$ in O. garnettii (Table 1). In $O$. crassicaudatus, the neuronal layer of the VNNE ranged from 43.4 to $46.8 \mu \mathrm{m}$ (61-63\% of total VNNE thickness) in males and from 31.2 to $41.3 \mu \mathrm{m}$ (57-63\% of total VNNE thickness). In O. garnettii, the neuronal layer of the VNNE ranged from 35.5 to $42.2 \mu \mathrm{m}(61-63 \%$ of total VNNE thickness) in males and from 34.9 to $44.2 \mu \mathrm{m}$ (58-62\% of total VNNE thickness) in females. In the infant $O$. garnettii, the neuronal layer of the VNNE was $31.1 \mu \mathrm{m}$ (61.9\% of total VNNE thickness) (Table 1).

Average VRN nuclear diameter was larger in female $(9.5 \mu \mathrm{m})$ than male $(7.42 \mu \mathrm{m})$ O. crassicaudatus, but was
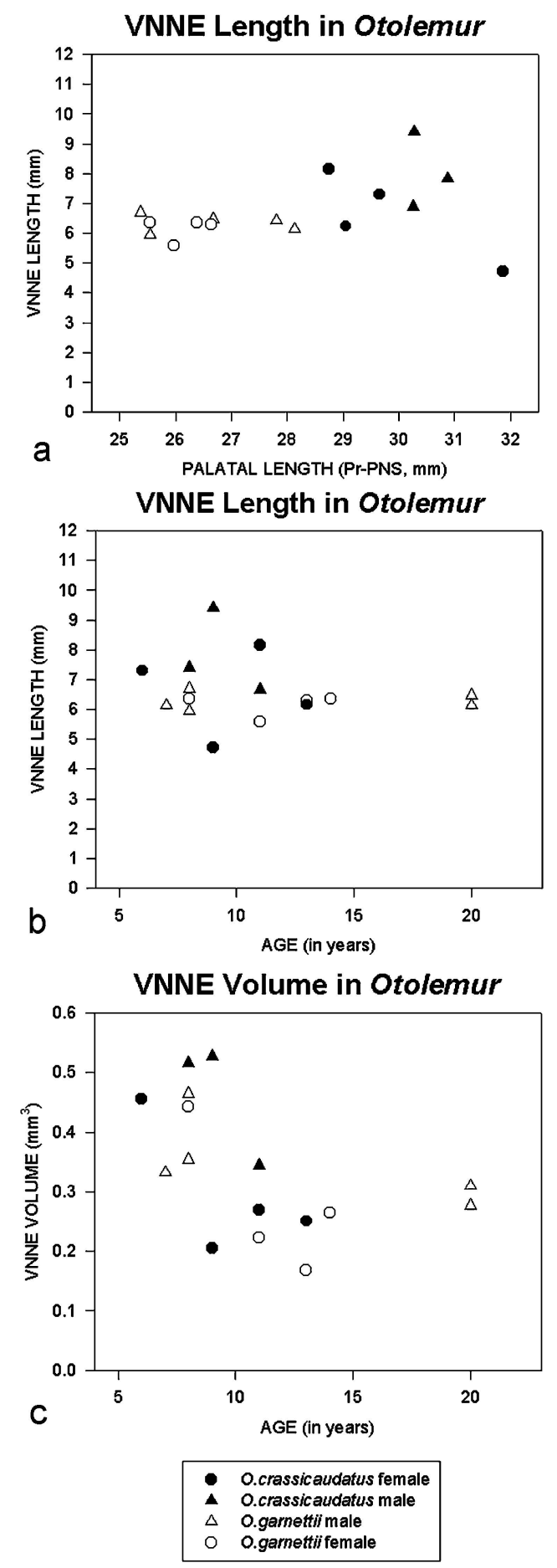

Fig. 4. Scatter plots of vomeronasal neuroepithelial (VNNE) length against (a) palatal length and (b) age. (c) Scatter plot of VNNE volume against age. Note no positive relationship exists between VNNE length and palatal length, and greater variation in VNNE length is seen for $O$. crassicaudatus. Note that no increase or decrease in VNNE length is associated with increasing age. At similar ages, males of both species, especially O. crassicaudatus, had larger VNNE volumes, but note that a similar trend of decreasing VNNE size is suggested for both sexes of both species (VNNE volume is nearly $50 \%$ smaller in specimens from 10-20 years compared to most younger specimens). 
Table 3. Quantitative investigations on the vomeronasal neuroepithelium (VNNE) of some mammals.

\begin{tabular}{|c|c|c|c|c|c|c|}
\hline $\begin{array}{l}\text { Strain or Species, } \\
\text { common name }\end{array}$ & $\begin{array}{l}\text { VNNE receptor } \\
\text { neuron nuclei } / \mathrm{mm}^{2}\end{array}$ & \# VRNs & $\begin{array}{l}\text { Nuclear } \\
\text { size }(\mu \mathrm{m})\end{array}$ & $\begin{array}{l}\text { VNNE } \\
\text { length }(\mu \mathrm{m})\end{array}$ & $\begin{array}{l}\text { VNNE } \\
\text { volume }\left(\mathrm{mm}^{3}\right)\end{array}$ & Source \\
\hline Sprague-Dawley rat & 9,300 to 16,000 (days $66-450$ ) & & & & & Weiler et al., 1999a \\
\hline Wistar rat & - & $\begin{array}{l}37961(\mathrm{~m}) \\
30175(\mathrm{f})\end{array}$ & & & $\begin{array}{l}0.184(\mathrm{~m}) \\
0.113(\mathrm{f})\end{array}$ & $\begin{array}{l}\text { Segovia \& Guillamón, } \\
\text { 1982, } 1993\end{array}$ \\
\hline $\begin{array}{l}\text { Oryctolagus cuniculus, } \\
\text { Rabbit }\end{array}$ & & $1,650,000$ & & & 0.96 & Negus, 1958 \\
\hline $\begin{array}{l}\text { Mustela putorius furo, } \\
\text { Ferret (males only) }\end{array}$ & & & & & 0.113 to 0.159 & Weiler et al., 1999b \\
\hline Microtus fortis, reed vole & $\begin{array}{l}4510(\mathrm{~m}) \\
3218(\mathrm{f})\end{array}$ & - & $\begin{array}{l}5.08(\mathrm{~m}) \\
5.15(\mathrm{f})\end{array}$ & $\begin{array}{l}512.4(\mathrm{~m}) \\
417.9(\mathrm{f})\end{array}$ & - & Tai et al., 2004 \\
\hline $\begin{array}{l}\text { Microtus mandarinus, } \\
\text { mandarin vole }\end{array}$ & $\begin{array}{l}4040(\mathrm{~m}) \\
3840(\mathrm{f})\end{array}$ & - & $\begin{array}{l}5.33(\mathrm{~m}) \\
5.25(\mathrm{f})\end{array}$ & $\begin{array}{l}369.6(\mathrm{~m}) \\
395.9(\mathrm{f})\end{array}$ & - & Tai et al., 2004 \\
\hline $\begin{array}{l}\text { Microtus ochrogaster, } \\
\text { prairie vole }\end{array}$ & $14,775(\mathrm{~m})$ & - & - & $\begin{array}{l}3174(\mathrm{~m}) \\
3140(\mathrm{f})\end{array}$ & $\begin{array}{l}0.156(\mathrm{~m}) \\
0.155(\mathrm{~m})\end{array}$ & $\begin{array}{l}\text { Smith et al., 2001a; Maico } \\
\text { et al., } 2003\end{array}$ \\
\hline $\begin{array}{l}\text { Microtus pennsylvanicus, } \\
\text { meadow vole }\end{array}$ & $15,677(\mathrm{~m})$ & - & - & $3201(\mathrm{~m})$ & $0.158(\mathrm{~m})$ & Smith et al., 2001a; Maico \\
\hline $\begin{array}{l}\text { Artibeus jamaicensis, } \\
\text { Mexican fruit bat }\end{array}$ & & $\begin{array}{l}\quad 396 \\
\text { cell bodies in a } \\
\text { paravomeronasal } \\
\text { ganglion }\end{array}$ & & $3210(\mathrm{f})$ & 0.194 (f) & $\begin{array}{l}\text { et al., } 2003 \\
\text { Bhatnagar \& Kallen, } 1974\end{array}$ \\
\hline $\begin{array}{l}\text { Nycticebus coucang, } \\
\text { slow loris }\end{array}$ & 92,000 & & & & & Hedewig, 1980b \\
\hline $\begin{array}{l}\text { Otolemur crassicaudatus, } \\
\text { thick-tailed bushbaby }\end{array}$ & 61,000 & & & & & Hedewig, 1980a \\
\hline $\begin{array}{l}\text { Otolemur crassicaudatus, } \\
\text { thick-tailed bushbaby }\end{array}$ & $\begin{array}{l}11,357(\mathrm{~m}) \\
11,944(\mathrm{f})\end{array}$ & - & & $\begin{array}{l}7900(\mathrm{~m}) \\
6370(\mathrm{f})\end{array}$ & $\begin{array}{l}0.46(\mathrm{~m}) \\
0.29(\mathrm{f})\end{array}$ & this study \\
\hline $\begin{array}{l}\text { Otolemur garnettii, } \\
\text { Garnett's bushbaby }\end{array}$ & $\begin{array}{l}12,530(\mathrm{~m}) \\
12,879(\mathrm{f})\end{array}$ & - & & $\begin{array}{l}6340(\mathrm{~m}) \\
6150(\mathrm{f})\end{array}$ & $\begin{array}{l}0.36(\mathrm{~m}) \\
0.27(\mathrm{f})\end{array}$ & this study \\
\hline Microcebus murinus & - & 209,000 & - & & & Schilling, 1970 \\
\hline
\end{tabular}

similar in female $(8.9 \mu \mathrm{m})$ and male $(8.63 \mu \mathrm{m})$ O. garnettii (Table 1). In the infant $O$. garnettii, VRN nuclear diameter was $5.73 \mu \mathrm{m}$ (Table 1 ).

In adults, palatal length (prosthion-posterior midpoint of palate) ranged from 28.75 to $31.86 \mathrm{~mm}$ in $O$. crassicaudatus and from 25.38 to $28.14 \mathrm{~mm}$ in O. garnettii. The anteroposterior extent of the duct of the VNO, conversely, was greater in $O$. garnettii $(1.06$ to $2.15 \mathrm{~mm}$ ) than in $O$. crassicaudatus ( 0.7 to $1.44 \mathrm{~mm}$ ). Length of the VNNE ranged from 4.72 to $9.42 \mathrm{~mm}$ in $O$. crassicaudatus and from 5.6 to $6.7 \mathrm{~mm}$ in 0. garnettii (Table 1); this corresponded to a range of 15 to $31 \%$ of palatal length for the sample as a whole (males: $22-31 \%$; females: $15-28 \%$ ). When plotted relative to palatal length or age, adult VNNE length was negatively allometric (Fig. 4a), showing no increase of decrease relative to the $x$-axis. These plots revealed greater variation in the VNNE length of $O$. crassicaudatus compared to
O. garnettii. Examination of the plots suggested no sex differences in VNNE between male and female $O$. garnettii. In O. crassicaudatus, males appeared to have greater VNNE length than females (with overlapping ranges), as suggested by the means presented in Table 2.

VNNE length was $3.2 \mathrm{~mm}$ in the neonatal $O$. crassicaudatus and $3.1 \mathrm{~mm}$ in the neonatal $O$. garnettii. There was at least a two-fold difference when comparing the VNNE length in neonates to the mean adult VNNE length for either species (Table 2).

VNNE volume ranged from 0.205 to $0.527 \mathrm{~mm}^{3}$ in $O$. crassicaudatus and from 0.168 to $0.465 \mathrm{~mm}^{3}$ in $O$. garnettii. A plot of VNNE volume showed larger volumes for younger animals and that males had the highest and lowest volumes at comparable ages compared to females (Fig. 4c). Average adult VNNE volume was about $60 \%$ higher in male compared to female $O$.

Fig. 5. Co-labeled OMP (green)/BT (red) preparations of female $(5 \mathrm{a}, \mathrm{c})$ and male $(5 \mathrm{~b}, \mathrm{~d})$ O. crassicaudatus (top) and O. garnettii. Note the extensive OMP immunofluorescence of vomeronasal receptor cell bodies (open arrows) and BT immunofluorescence of dendrites (short arrows). Double labeling (yellow) is seen in some dendrites of receptor neurons (5b, c, d) and more rarely in cell bodies $(5 b)$. Note the relatively thicker neuroepithelium in males $(5 b, d)$ especially dorsally and ventrally, adjacent to the receptor-free epithelium (RFE). The OMP-positive reaction on the apical surface of RFE (Fig. 5d) was most likely nonspecific binding to tissue refuse adhering to the slide. Scale bars $=100 \mu \mathrm{m}$. 

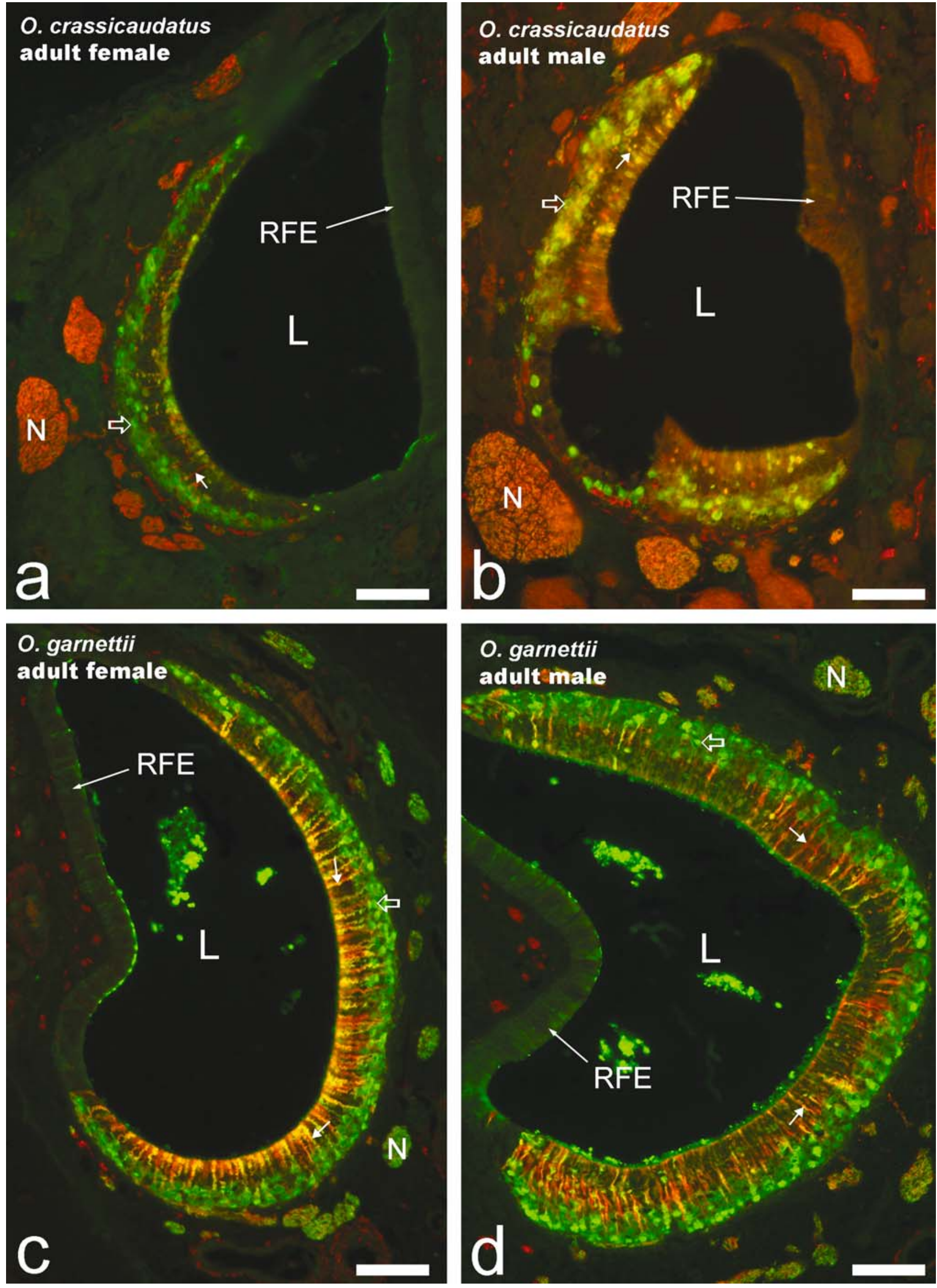
crassicaudatus and about $30 \%$ higher in male compared to female $O$. garnettii (Table 2). VNNE volume for the neonatal male O. garnettii was $0.073 \mathrm{~mm}^{3}$, a $389 \%$ difference compared to adult male $O$. garnettii.

ANOVA comparisons revealed significant $(p<0.05)$ differences between species for palatal length, but no significant $(p>0.05)$ sex or interaction (species $\mathrm{x}$ sex) effects were found (Table 2). No significant species, sex, or interaction effects were found for VNNE length. For VNNE volume ANOVA comparisons revealed significant $(p<0.05)$ differences in between sexes but not for species or interaction effects (Table 2).

Immunohistochemical procedures revealed BT and OMP immunoreactivity was present in the VNNE of all specimens studied, including the neonatal $O$. garnettii (Fig. 3b). Colabeled OMP/BT preparations supported observations from hematoxylin-eosin and Gomori trichrome procedures that adult males of both species generally had a thicker VNNE (Fig. 5). However, the difference appeared to be most profound where the ventral and dorsal margins of the VNNE joined the receptor-free epithelium. At these positions, VRNs were more numerous in males (cf. Figs. 5a, c; Figs. 5b, d).

\section{Discussion}

Strepsirrhine primates (lemurs, lorises and bushbabies) are thought to possess many similarities to stem primate ancestors in the nasal region (Fleagle, 1999). As such, they provide the most appropriate model to understand primitive aspects of the accessory olfactory system in primates. In this regard, the present study supports existing notions that strepsirrhines have VNOs that resemble those of other mammals with functional VNOs (Bhatnagar \& Meisami, 1998; Hunter et al., 1987; Loo \& Kanagasuntheram, 1972; Smith et al., 2002).

Not surprisingly, strepsirrhines are the only primates in which the VNO was experimentally shown to mediate reproductive behaviors (Aujard, 1997). Recent immunohistochemical findings indicate that representatives of the two infraorders of Strepsirrhini, Lemuriformes and Lorisiformes, possess VNOs that express OMP (Dennis et al., 2004), a neuronal marker of mature olfactory and vomeronasal neurons (Farbman \& Margolis, 1980; Margolis, 1980). Dennis et al. (2004) also demonstrated that OMP was expressed at birth in species of the lemuriform genus Eulemur. The findings of the present study suggest this is also true of the lorisiform Otolemur garnettii. Further investigations of the immunocharacteristics of the neonatal VNO are merited, especially since in another lorisiform, Nycticebus coucang, the VNO was described to be rudimentary at birth (Evans \& Schilling, 1995; although it is welldeveloped in adults---Hedewig, 1980b).
The significance of immunohistochemical findings using double labeling with BT and OMP is presently unknown. Dennis et al. (2004) hypothesized that, with regard to BT and OMP expression, primate vomeronasal sensory neurons follow a developmental program similar to that of sensory neurons of the rat main olfactory epithelium. In those cells, BT is expressed first followed by OMP expression and a down regulation of $\mathrm{BT}$ in the cell body (Lee \& Pixley, 1994).

The present study suggests minimal interspecies differences among adults of the genus Otolemur with respect to VNNE size, VRN nuclear density, VNNE microstructure, or patterns of OMP/BT immunoreactivity. The two bushbabies are dissimilar in other respects such as palatal length and also size and histological structure of the vomeronasal duct. Our findings on the significant size differences in the length of the palate are in agreement with previous findings on larger cranial and postcranial dimensions in O. crassicaudatus (Dixson \& van Horn, 1977), and in this sense, the interspecies similarity in VNNE size is a marked contrast. With respect to previous estimates of VRN nuclear density (Table 3$)$, the results herein $(10,122$ to 13,332 nuclei per $\mathrm{mm}^{2}$ ) are broadly comparable with data available on other adult mammals, such as rats (Weiler et al., 1999a). However, these data conflict sharply with previous estimates of VRN nuclear density in $O$. crassicaudatus provided by Hedewig (1980a). Since the total VRN numbers per VNO in rats is approximately 500,000 to 650,000 (Weiler et al., 1999a) and in the mouse lemur is 210,000 (Schilling, 1970), we believe the estimates provided by Hedewig for $O$. crassicaudatus (1980a; 61,000 per $\mathrm{mm}^{2}$ ) and Nycticebus coucang (1980b; 92,000 per $\mathrm{mm}^{2}$ ) are inaccurate.

Intraspecies variation in VNNE size is indicated herein, both age-related and probably also sex-related. If the neonates measured in this study are typical in VNNE size, the increase from birth to adulthood is on the same order of magnitude as seen for rats (Weiler et al.,1999a). The availability of adult specimens is problematic for interpretation of adult age-related changes, but the distribution of VNNE volume across age suggests a trend toward postnatal reduction, with the highest volumes seen from six to nine years, and both sexes following the same trend (Fig. 4c). It is important to note that all animals were part of a breeding colony and had intact reproductive organs prior to euthanasia. Generally, the younger, sexually mature animals were used in breeding (P. Sullivan, Duke University Medical Center, personal communication), suggesting that endocrine differences relating to reproductive behavior may have existed among animals. On the other hand, the apparent trend of VNNE reduction may relate other variables besides reproductive biology. For instance, age-related reduction in size or neuronal numbers of olfactory structures have been documented in various mammals. From four to eighteen months of age, 
sexually mature albino mice have significant decreases in VRN nuclear density and total VRN numbers per VNO (Wilson \& Raisman, 1980). Age-related reduction is also well documented for structures of the main olfactory system in humans (Bhatnagar et al., 1987; Meisami et al., 1998) and mice (Hinds \& McNelly, 1977). More notably, a recent study on captive mouse lemurs (Microcebus murinus), revealed an age-related decline in the olfactory abilities as well as endocrine responses of males to female urine (Aujard \& Nemoz-Bertholet, 2004), a phenomenon for which VNNE deficits may also play a role.

The present study indicated significant sex differences in VNNE volume, with males $>$ females. It should be emphasized that we did not test for sex differences within each species, in which our sample sizes were too small. However, intersexual differences in VNNE volume appeared to be greater in O. crassicaudatus than O. garnettii (Fig. 4c; Table 2). Since the dimorphism in body weight and skeletal measures is greater in O. crassicaudatus relative to O. garnettii (Dixson \& van Horn, 1977; Rowe, 1996) the possibility exists that VNNE size differences simply reflect overall somatic dimorphism. Unfortunately, body weights were not available for the specimens examined herein and only partial crania were available for measurement. However, in our Otolemur sample it is noteworthy that VNNE dimorphism exceeded intersexual differences in palatal length. Palatal length was very similar between sexes (30.5 vs. 29.8 and 26.7 vs. 26.1 for O. crassicaudatus and O. garnettii, respectively). Regardless, the practice of comparing the size of olfactory structures between males and females as an adjusted measure (i.e., relative to body size) has been criticized (Maico et al., 2003; Smith \& Bhatnagar, 2004). Indeed, once data on any sensory structure is scaled to body weight or overall brain weight, it may be difficult to determine whether proportional measurements are indicative of fluctuations in the numerator or denominator (e.g., is a proportionately small olfactory bulb a reflection of a small olfactory bulb or an extremely expanded cerebral cortex?)(Glendenning \& Masterson, 1998; Smith \& Bhatnagar, 2004).

Smith \& Bhatnagar (2004) recommended that comparative studies using VNNE size as a proxy for VRN numbers should control for differences in VRN density, instead of body size. VRN nuclear densities are similar in range between males and females in each species of Otolemur (Table 1). Thus, VNNE volume measurements in Otolemur spp. would appear to reflect a similar number of neurons per $\mathrm{mm}^{3}$ in both sexes, rendering body size differences irrelevant. Since only specimens sectioned at $10 \mu \mathrm{m}$ were used for this purpose (see methods), the implication of VNNE volume data to overall VRN numbers remains tentative. Data on VRN nuclear diameter combined with those on VRN nuclear density suggest that males do not have larger VNNE vol- ume due to larger VRN size. Moreover, the neuronal portion of the VNNE was roughly proportional in all species/sex (ranging only from about 57 to $63 \%$ ). This excludes the possibility that the largely non-neuronal, apical part of the VNNE is responsible for dimorphism in volume.

Qualitative observations of the distribution of BTand/or OMP-immunoreactive neurons suggested specific differences between males and females. Male Otolemur typically have a greater number of VRNs at the dorsal and ventral margins of the VNNE (directly adjacent to the RFE) than females. Thus a possible proximal basis for sexually dimorphic size may be greater proliferative activity at the VNNE margins in males. Interestingly, VRNs proliferating at the marginal regions of the VNNE in mammals have different fates than VRNs in the intermediate zone of the VNNE (Halpern \& Martínez-Marcos, 2003; Martínez-Marcos et al., 2005; Takami, 2002). The possibility that VRN proliferation is more rapid in specific portions of the VNNE in male bushbabies can be tested further with other IHC procedures.

The results of this study suggest greater bushbabies are similar to a number of other vertebrate species in possessing sexually dimorphic VNNE volume (Dawley \& Crowder, 1995; Maico et al., 2003; Segovia \& Guillamón, 1982; Tai et al., 2004). Sexual dimorphism of the VNNE with males $>$ females has been hypothesized to relate to mate-finding behaviors (Dawley \& Crowder, 1995) or to polygamous mating strategies (Tai et al., 2004). The results of the present study lend support to either hypothesis in that the genus Otolemur has a dispersed multimale social system in which males have home ranges overlapping those of multiple females (Nash \& Harcourt, 1986; Müller \& Thalmann, 2000). The significance of these findings to behavior, if any, is unknown. Some sexually specific behaviors and endocrine responses are known to be mediated by the VNO in other mammals (Thompson et al., 2004). Therefore, further investigation of sexually dimorphic aspects of the VNO in strepsirrhines as well as behavioral correlates is warranted.

\section{Acknowledgments}

The authors thank the guest editors of this special issue for the kind invitation to submit our paper. We thank Dr. Frank Margolis, University of Maryland School of Medicine, for the generous gift of the anti-OMP antisera used in this study. We are grateful to Dr. Patrick Sullivan, Duke University School of Medicine, for providing a personal communication and for numerous courtesies in obtaining information on the colony of bushbabies. In accordance with the request of Duke University Primate Center, who gave us access to the newborn primate cadavers used herein, this paper has been assigned as DUPC publication \#775. Finally, we 
are grateful for grants from Slippery Rock University (to TDS, AMB), Federal Aviation Administration \#01-6022 (to EEM) and US Army Robert Morris Acquisition Center, contract \#N66001-1099-0072 (to EEM).

\section{Notes}

1. Terminology for the vomeronasal organ varies. Herein, we follow the usage of Bhatnagar and Meisami (1998) and Smith et al. (2001a, 2002) which considers the VNO to comprise a neuroepithelial tube that, in many species, also includes a receptor-free zone. Other authors use the term "vomeronasal duct" for what we have termed the VNO (Salazar \& Sanchez Quinteiro, 1998). We use the term vomeronasal duct for the epithelial tube that transports stimuli from nasopalatine duct to the VNO.

2. Tests of repeatability using preliminary data (Smith et al., 2003) revealed that these calculations were unreliable in specimens sectioned thicker than $10 \mu \mathrm{m}$.

\section{References}

ABOLMAALI, N. D., KUHNAU, D., KNECHT, M., KOHLER, K., HUTTENBRINK, K. B. \& HUMMEL, T. (2001) Imaging of the human vomeronasal duct. Chemical Senses 26, 35-39.

ADDISON, W. H. F. \& RADEMAKER, L. A. (1927) The postnatal growth of the vomeronasal organ of the albino rat (Mus norvegicus albinus). Journal of Comparative Neurology 44, 69-86.

AUJARD, F. (1997) Effect of vomeronasal organ removal on male socio-sexual responses to female in a prosimian primate (Microcebus murinus). Physiology \& Behavior 62, 1003-1008.

AUJARD, F. \& NEMOZ-BERTHOLET, F. (2004) Response to urinary volatiles and chemosensory function decline with age in a prosimian primate. Physiology $\mathcal{E}$ Behavior 81, 639-44.

BHATNAGAR, K. P. \& KALLEN, F. C. (1974) Morphology of the nasal cavities and associated structures in Artibeus jamaicensis and Myotis lucifugus. American Journal of Anatomy 139, 167-189.

BHATNAGAR, K. P. \& MEISAMI, E. (1998) Vomeronasal organ in bats and primates: Extremes of structural variability and its phylogenetic implications. Microscopy Research \& Technique 43, 465-475.

BHATNAGAR, K. P., KENNEDY, R. C., BARON, G. \& GREENBERG, R. A. (1987) Number of mitral cells and the bulb volume in the aging human olfactory bulb: A quantitative morphological study. Anatomical Record 218, 73-87.

DAWLEY, E. M. (1998) Species, sex, and seasonal differences in VNO size. Microscopy Research \& Technique 41, 506-518.

DAWLEY, E. M. \& CROWDER, J. (1995) Sexual and seasonal differences in the vomeronasal epithelium of the red-backed salamander (Plethodon cinereus). Journal of Comparative Neurology 359, 382-390.

DENNIS, J. C., SMITH, T. D., BHATNAGAR, K. P., BURROWS, A. M., BONAR, C. J. \& MORRISON, E. E. (2004) Expression of neuron-specific markers by the vomeronasal neuroepithelium in six primates species. Anatomical Record 281A, 1190-1199.

DIXSON, A. F. \& VAN HORN, R. N. (1977) Comparative studies of morphology and reproduction in two subspecies of the greater bushbaby,Galago crassicaudatus crassicaudatus and G. c. argentatus. Journal of Zoology, London 183, 517-526.

EATON, G. G., SLOB, A. \& RESKO, J. A. (1973) Cycles of mating behaviour, estrogen and progesterone in the thick-tailed bushbaby (Galago crassicaudatus crassicaudatus) under laboratory conditions. Animal Behaviour 21, 309-315.

EVANS., C. \& SCHILLING, A. (1995) The accessory (vomeronasal) chemoreceptor system in some prosimians. In Creatures of the Dark: The Nocturnal Prosimians. (edited by ALTERMAN, L., DOYLE, G.A. \& IZARD, M.K.) pp. 393-411. New York: Plenum.

FARBMAN, A. I. \& MARGOLIS, F. L. (1980) Olfactory marker protein during ontogeny: Immunohistochemical localization. Developmental Biology 74, 205-215.

FLEAGLE, J. G. (1999) Primate Adaptation and Evolution. 2nd Edition. San Diego: Academic Press.

GLENDENNING, K. K. \& MASTERSON, R. B. (1998) Comparative morphometry of mammalian central auditory systems: Variation in nuclei and form of the ascending system. Brain, Behavior, E Evolution 51, 59-89.

HALPERN, M., MARTÍNEZ-MARCOS, A. (2003) Structure and function of the vomeronasal system: An update. Progress in Neurobiology 70, 245-318.

HEDEWIG, R. (1980a) Vergleichende anatomische untersuchungen an den Jacobsonschen organen von $\mathrm{Nyc}$ ticebus coucang Boddaert, 1785 (Prosimiae, Lorisidae) und Galago crassicaudatus E. Geoffroy, 1812 (Prosimiae, Lorisidae).II.Galago Crassicaudatus. Gegenbaurs Morphologishes Jahrbuche 126, 676-722.

HEDEWIG, R. (1980b) Vergleichende anatomische untersuchungen an den Jacobsonschen organen von Nycticebus coucang Boddaert, 1785 (Prosimiae, Lorisidae) und Galago crassicaudatus. E. Geoffroy, 1812 (Prosimiae, Lorisidae).I. Nycticebus coucang. Gegenbaurs Morphologishes Jahrbuche 126, 543-593.

HINDS, J. W. \& MCNELLY, N. A. (1977) Aging of the rat olfactory bulb: Growth and atrophy of constituent layers and changes in size and number of mitral cells. Journal of Comparative Neurology 72, 345367.

HUNTER, A. J., FLEMING, D. \& DIXSON, A. F. (1984) The structure of the vomeronasal organ and nasopalatine ducts in Aotus trivirgatus and some other primate species. Journal of Anatomy 138, 217-225.

LEE, V. M. \& PIXLEY, S. K. (1994) Age and differentiationrelated differences in neuron-specific tubulin immunostaining of olfactory sensory neurons. Developmental Brain Research 83, 209-215.

LOO, S. K. \& KANAGASUNTHERAM, R. (1972) The vomeronasal organ in tree shrew and slow loris. Journal of Anatomy 112, 165-172.

MAICO, L. M., BURROWS, A. M., MOONEY, M. P., SEIGEL, M. I., BHATNAGAR, K. P. \& SMITH, T.D. (2003) Size of the vomeronasal organ in wild Microtus with different mating strategies. Acta Biologica Hungarica 54, 263-273. 
MARGOLIS, F. L. (1980) A marker protein for the olfactory chemoreceptor neuron. In Proteins of the Nervous System (edited by BRADSHAW, R. A. \& SCHNEIDER, D.) pp. 59-84. New York: Raven.

MARTÍNEZ-MARCOS, A., JIA, C., QUAN, W. \& HALPERN, M. (2005) Neurogenesis, migration, and apoptosis in the vomeronasal epithelium of adult mice. Journal of Neurobiology 63, 173-187.

MEISAMI, E. (1989) A proposed relationship between increases in the number of olfactory receptor neurons, convergence ratio and sensitivity in the developing rat. $D e-$ velopmental Brain Research 46, 9-19.

MEISAMI, E., LOUIE, J., HUDSON, R.\& DISTEL, H. (1990) A morphometric comparison of the olfactory epithelium of newborn and weanling rabbits. Cell $\mathcal{E}$ Tissue Research 62, 89-97.

MEISAMI, E., MIKHAIL, L., BAIM, D. \& BHATNAGAR, K. P. (1998) Human olfactory bulb: Aging of glomeruli and mitral cells and a search for the accessory olfactory bulb. Annals of the New York Academy of Sciences 855, 708-715.

MÜLLER, A. E. \& THALMANN, U. (2000) Origin and evolution of primate social organisation: A reconstruction. Biological Reviews of the Cambridge Philosophical Society 75, 405-435.

NASH, L. T. \& HARCOURT, C. S. (1986) Social organization of galagos in Kenyan coastal forests: II: Galago garnettii. American Journal of Primatology 10, 357-369.

NEGUS, V. (1958) The comparative anatomy and physiology of the nose and paranasal sinuses. Edinburgh and London: Livingston.

ROWE, N. (1996) The Pictorial Guide to the Living Primates. Charlestown: Pogonias Press.

SALAZAR I. \& SANCHEZ QUINTEIRO, P. (1998) Supporting tissue and vasculature of the mammalian vomeronasal organ: The rat as a model. Microscopy Research \& Technique 41, 492-505.

SCHILLING, A. (1970) L'organe de Jacobson du lemurien malgache Microcebus murinus (Miller, 1977). Memoires du Museum National d'Histoire Naturelle (Serie A) 61, 203-280.

SCHMECHEL, D.E., BURKHART, D.S., ANGE, R. \& IZARD, M.K. (1996) Cholinergic axonal dystrophy and mitochondrial pathology in prosimian primates. Experimental Neurology 142, 111-127.

SEGOVIA, S. \& GUILLAMÓN, A. (1982) Effects of sex steroids on the development of the vomeronasal organ in the rat. Developmental Brain Research 5, 209-212.

SEGOVIA, S. \& GUILLAMÓN, A. (1993) Sexual dimorphism in the vomeronasal pathway and sex differences in reproductive behaviors. Brain Research Reviews 18, 5174.

SHERWOOD, R. J., MCLACHLAN, J. C., AITON, J. F. \& SCARBOROUGH, J. (1999) The vomeronasal organ in the human embryo, studied by means of threedimensional computer reconstruction. Journal of Anatomy 195, 413-418.

SMITH, T. D. \& BHATNAGAR, K. P. (2004) Microsmatic primates: Reconsidering how and when size matters. Anatomical Record 279B, 24-31.

SMITH, T. D., SIEGEL, M. I., MOONEY, M. P., BURDI, A. R. \& TODHUNTER, J. S. (1996) Vomeronasal organ growth and development in normal and cleft lip and palate fetuses. Cleft Palate-Craniofacial Journal 33, 385-394. SMITH, T. D., SIEGEL, M. I., MOONEY, M. P., BURDI, A. R., BURROWS, A. M. \& TODHUNTER, J. S. (1997) Prenatal growth of the human vomeronasal organ. Anatomical Record 248, 447-455.

SMITH, T. D., ROSLINSKI, D. L., BURROWS, A. M., BHATNAGAR, K. P., MOONEY, M. P. \& SIEGEL, M. I. (2001a) Size of the vomeronasal neuroepithelium in two species of Microtus with differing levels of paternal behavior. Journal of Mammalogy 82, 209-217.

SMITH, T. D., MOONEY, M. P., BURROWS, A. M., BHATNAGAR, K. P. \& SIEGEL, M. I. (2001b) Prenatal growth and adult size of the vomeronasal organ in mouse lemurs and humans. In Chemical Signals in Vertebrates IX (MARCHLEWSKA-KOJ, A., LEPRI, J.J. \& MÜLLER-SCHWARZE, D.) pp. 93-99. New York: Kluwer Academic/Plenum Press.

SMITH, T. D., SHIMP, K. L., BURROWS, A. M., SMITH, M. A. \& BHATNAGAR, K. P. (2003) Sexual dimorphism in the vomeronasal organ of Otolemur. American Journal of Physical Anthropology, Supplement 36, 196 (abstract).

SMITH, T. D., BHATNAGAR, K. P., SHIMP, K. L., KINZINGER, J. H., BONAR, C. J., BURROWS, A. M., MOONEY, M. P. \& SIEGEL, M. I. (2002) Histological definition of the vomeronasal organ in humans and chimpanzees, with a comparison to other primates. Anatomical Record 267, 166-176.

SOKAL, R. R. \& ROHLF, F. J. (1982). Biometry. New York: WH Freeman and Company.

STEPHAN, H., BARON, G. \& FRAHM, H. D. (1982) Comparison of brain structure volumes in Insectivora and Primates. II. Accessory olfactory bulb (AOB). Journal fur Hirnforschung 23, 575-591.

TAKAMI, S. (2002) Recent progress in the neurobiology of the vomeronasal organ. Microscopy Research $\mathcal{E}$ Technique $58,228-250$.

TAI, F. D., WANG, T. Z., ZHANG, Y. H. \& SUN, R. Y. (2004) Sexual dimorphism of the vomeronasal organ and the accessory olfactory bulb of the mandarin vole Microtus mandarinus and the reed vole M. fortis. Acta Theriologica 49, 33-42.

THOMPSON, R. N., ROBERTSON, B. K., NAPIER, A. \& WEKESA, K. S. (2004) Sex-specific responses to urinary chemicals by the mouse vomeronasal organ. Chemical Senses 29, 749-754.

WATSON, S. L., WARD, J. P., DAVIS, K. B. \&STAVISKY, R. C. (1999) Scent-marking and cortisol response in the small-eared bushbaby (Otolemur garnettii). Physiology $\mathcal{E}$ Behavior 66, 695-699.

WEILER, E., MCCULLOCH, M. A. \& FARBMAN, A. I. (1999a) Proliferation in the vomeronasal organ of the rat during postnatal development. European Journal of Neuroscience 11, 700-711.

WEILER, E., APFELBACH R. \& FARBMAN, A. I. (1999b) The vomeronasal organ of the male ferret. Chemical Senses 24, 127-136.

WILSON, K. C. P. \& RAISMAN, G. (1980) Age-related changes in the neurosensory epithelium of the mouse vomeronasal organ: Extended period of postnatal growth in size and evidence for rapid cell turnover in the adult. Brain Research 185, 103-113. 